The Egyptian Journal of Hospital Medicine (2009) Vol., 36 : 421 - 433

\title{
The analgesic and sedative properties of dexmedetomidine infusion after uvulopalatopharyngoplasty W.Abd El Megid ${ }^{1 *}$ and Ahmed M. Nassar ${ }^{2}$ \\ ${ }^{1}$ Department of Anesthesia and Intensive Care, Ain Shams University. ${ }^{2}$ Department of ENT, Al Azhar University.
}

\begin{abstract}
Background: Dexmedetomidine is an alpha ${ }_{2}$ - adrenergic agonist with sedative and analgesic properties. This study aimed to investigate if the use of continuous dexmedetomidine infusion with i.v. morphine patient-controlled analgesia (PCA) could improve postoperative analgesia while reducing opioid consumption and opioid-related side effects.

Materials \& methods: In this prospective randomized, double-blinded, controlled study, 24 patients with obstructive sleep apnea syndrome undergoing uvulopalatopharyngoplasty were assigned to two groups. Group D received a loading dose of dexmedetomidine $1 \mu \mathrm{g} \mathrm{kg}^{-1}$ i.v., 30 min before the anticipated end of surgery, followed by a continuous infusion at a rate of $0.6 \mu \mathrm{g}$ $\mathrm{kg}^{-1} \mathrm{hr}^{-1}$ for $24 \mathrm{hr}$. Group P received a volume-matched bolus and infusion of placebo. In both groups, postoperative pain was initially controlled by i.v. morphine titration and then PCA with morphine. Cumulative PCA morphine consumption, pain intensities, sedation scores, cardiovascular and respiratory variables and narcotic-related adverse effects were recorded for 48 $\mathrm{h}$ after operation.
\end{abstract}

Results: Extubation time was significantly prolonged in dexmedetomidine group (16 \pm 7 vs. $11 \pm 6$ $\min \mathrm{p}=0.074)$ in the placebo group. Visual analogue scale scores were significantly greater during the first $2 \mathrm{~h}$ after tracheal extubation in the placebo group than in the dexmedetomidine group. The time to first analgesic request was significantly longer in the dexmedetomidine group than in the placebo group $(21 \pm 11$ vs. $9 \pm 4 \mathrm{~min} ; \mathrm{p}=0.002)$. Compared with group $\mathrm{P}$, patients in group $\mathrm{D}$ required $52.7 \%$ less morphine by PCA during the first $24 \mathrm{~h}$ postoperative period, whereas levels of sedation were similar between the 2 groups at each observational time point. Fewer patients in group $\mathrm{D}$ experienced nausea and vomiting than those in group $\mathrm{P}(\mathrm{P}<0.05)$. There was no bradycardia, hypotension, or respiratory depression. Continuous dexmedetomidine infusion may be a useful anesthetic adjuvant for patients who are susceptible to narcotic-induced respiratory depression.

Conclusion: Continuous infusion of dexmedetomidine for pain relief after uvulopalatopharyngoplasty significantly reduces the amount of PCA morphine used by the patients postoperatively without affecting their ventilatory parameters and was associated with fewer morphine-related side effects. This novel drug could become a useful anesthetic adjuvant for patients with obstructive sleep apnea who are susceptible to narcotic-induced respiratory depression.

Key words:Dexmedetomidine; Uvulopalatophayngoplasty; Morphine; Patient controlled analgesia.

\section{Introduction}

Obstructive sleep apnea (OSA) is a syndrome characterized by periodic, partial or complete upper airway obstruction resulting in the disruption of sleep and hypoxemia with potentially serious physiologic consequences. It has been estimated to affect $4 \%$ of men and $2 \%$ of women in middle age and has been identified as a major health problem (Kim \& Lee 2006).

Uvulopalatopharyngoplasty (uppp) is still the most commonly performed surgical procedure for the treatment of OSA (Zodpe et al., 2006). it is safe and effective (Lundkvist et al., 2009) Pain, which is 
caused by irritation of the nerve endings, inflammation, and pharyngeal muscle spasm, is a major complication of uppp and continues until mucosal recovery is complete(Zodpe et al., 2006) (Patrocinio et $a l .$, 2007). The treatment of post operative pain after uppp; which is usually severe during the first 24 hours after surgery presents a challenge(Nikanne et al.,2003) . Opioids can cause sedation and respiratory depression. Nonsteroidal anti-inflammatory drugs can increase postoperative bleeding (Virtaniemi et al., 2009). Thus, a drug that has few or no adverse effect, does not increase postoperative bleeding, and provides complete postoperative analgesia, or at least reduces the amount of analgesic used, is still needed to reduce the complications related to analgesia.

Dexmedetomidine is an $\alpha 2$ adrenoreceptor agonist that has a unique mechanism of action. The agent induces sedation and anxiolysis via receptors in the locus ceruleus, analgesia via receptors in the spinal cord and attenuation of the stress response without significant respiratory depression (Riker et al., 2009) Given its beneficial sedative and analgesic properties and limited adverse effect profile, dexmedetomidine may be useful in the postoperative period for patients with OSA who are susceptible to narcotic-induced respiratory depression and having surgical procedures that are associated with significant pain (Arain et al.,2004) \&(Hofer et al., 2005).

The aim of this study was to investigate whether continuous dexmedetomidine infusion provides effective analgesia and reduces the need for postoperative selfadministration of i.v. morphine and to assess if decreased morphine consumption is associated with a reduction in sedation, nausea and vomiting. Elimination of these adverse effects is important to facilitate recovery from surgery.

\section{Method}

This study took place in king Abdulaziz Navel Base Hospital, Jubail, KSA, from July 2007 to January 2009. The study was approved by the Hospital Ethics Committee and written informed consent was obtained from each patient. We studied 24 ASA I-II patients, aged 38-55 years with OSA and scheduled for uppp. Inclusion criteria include history of airway obstruction during sleep, frequent loud snoring and arousal from sleep. Physical examination was done to all patients for tonsillar size, palate tongue position and degree of hypertrophy of the lateral sides of the oropharynx. All patients underwent fibrooptic endoscopy with Muller's manouver, nasoendoscopy and Polysomnography and positive diagnosis of OSA was obtained before surgery. The apnea hypopnea index ranges from 20-40. The surgical procedure included tonsillectomy and resection of excess fat and mucosa in the soft palate including uvula with preservation of palpable musculature. Several sutures approximated the anterior and posterior pillars.

Patients were excluded if there was a history of ischemic heart disease, conduction disturbance, long term use of certain medications ( $\beta$-blockers, analgesics, sedatives or tricyclic antidepressant), if they had impaired renal, hepatic or pulmonary function, a history of allergy to opioids or any other drug used in the study, contraindications to the self-administration of opioid (i.e. inability to understand the patient-controlled analgesia (PCA) system). The evening before surgery, patients were instructed in the use of a $10-\mathrm{cm}$ visual analogue scale (VAS) on which $0-\mathrm{cm}$ represented no pain and $10-\mathrm{cm}$ the worst imaginable pain. The use of a (PCA) system 
(Fresenius vial, Brezins, France) was also explained at this time. No premedication was given and the anesthetic technique was standardized. Heart rate (HR), non invasive mean arterial pressure (MAP) and oxygen saturation (SpO2) were noted before induction and repeated at regular intervals thereafter. A forearm vein was cannulated for administration of anesthetics and Ringer's lactate solution was infused at a rate of $10 \mathrm{ml} \mathrm{kg}{ }^{-1} \mathrm{~h}^{-1}$. Patients were preoxygenated for $3 \mathrm{~min}$ by mask with $100 \%$ oxygen. Anesthesia was induced with propofol $2 \mathrm{mg} \mathrm{kg}^{-1}$, fentanyl $1 \mu \mathrm{g} \mathrm{kg}^{-1}$ and atracurium $0.5 \mathrm{mg} \mathrm{kg}^{-1}$ to facilitate orotracheal intubation. After tracheal intubation, the lungs were ventilated to maintain normocapnia (end-tidal carbon dioxide pressure (ETCo2) between 4.5 and $5.6 \mathrm{kPa}$ ) with $1-2 \%$ sevoflurane in $60 \%$ nitrous oxide and $40 \%$ oxygen for maintenance of anesthesia. Supplemental boluses of atracrium $0.1 \mathrm{mg} \mathrm{kg} \mathrm{kg}^{-1}$ were administrated as required to maintain muscle relaxation during surgery.

Randomization was carried out by computer-generated codes maintained in sequentially numbered, opaque envelopes, which were opened before induction of anesthesia. Patients were allocated randomly to one of two groups, $30 \mathrm{~min}$ before the anticipated end of surgery. Group D (Dexmedetomidine group) received a loading dose of dexmedetomidine $1 \mu \mathrm{g} \mathrm{kg}^{-1}$ in $100 \mathrm{ml}$ of normal saline (Precedex, Abbott Laboratories Inc., Abbott Park, IL,USA) over $20 \mathrm{~min}$ followed by an infusion of $0.6 \mu \mathrm{g} \mathrm{kg}^{-1} \mathrm{~h}^{-1}$. This rate was maintained uninterrupted for $24 \mathrm{~h}$ (until the end of the first post operative day). Group $\mathrm{P}$ (placebo group) received the same volume of normal saline as a loading dose followed by a continuous saline infusion.
Blinding was carried out by a nurse, not involved in the data collection, who made up syringes and infusions of dexmedetomidine and normal saline under sterile conditions such that they appeared identical.

At the end of surgery, residual neuromuscular block was antagonized with atropine $20 \mu \mathrm{g} \mathrm{kg}^{-1}$ and neostigmine $50 \mu \mathrm{g}$ $\mathrm{kg}^{-1}$. The trachea was extubated after recovery of adequate spontaneous ventilation (adequate respiratory rate and good oxygenation) with good muscle strength as evidenced by sustained head-lift test. Extubation time was noted. All patients were transferred to the post anesthesia care unit(PACU) where they were monitored and received oxygen via a face mask at $6 \mathrm{~L} / \mathrm{min}$ for $1 \mathrm{~h}$ and then at $4 \mathrm{~L} / \mathrm{min}$ until discharge from the PACU, $4 \mathrm{~h}$ after extubation.

Initially, pain was controlled only by titration of i.v. morphine administered by nurses who were blinded to the treatment group. Pain intensity was assessed by the patients during swallowing using a VAS. The first analgesic medication was given when the VAS reached $4 \mathrm{~cm}$ after extubation. Intravenous morphine $2 \mathrm{mg}$ at 10 min interval was titrated until the VAS decreased to $<4 \mathrm{~cm}$. Morphine consumption at this time was recorded. When the VAS was $<4 \mathrm{~cm}$ after titration, patients had access to a PCA device. This device was set to deliver morphine $1 \mathrm{mg}$ as an i.v. bolus with a lockout interval of $5 \mathrm{~min}$, without background infusion. This PCA regimen was continued as long as needed in the PACU and the surgical ward. Patients were encouraged to push the analgesicdemand button when they experienced pain, and to repeat until they felt pain relief. Lornoxicam 8mg i.v. was used as (rescue analgesic) if pain scores remained higher than 4 . The cumulative doses of morphine 
given by PCA were recorded at 12, 24, 36, $48 \mathrm{~h}$ postoperatively.

Pain scores were recorded using a VAS scale every 30 min during the first $2 \mathrm{~h}$, every 60 min during the next $10 \mathrm{~h}$ and every $4 \mathrm{~h}$ during the next $36 \mathrm{~h}$. The time between extubation and the first administration of analgesic medication was recorded.

Arterial blood samples for blood gases analysis were drawn at extubation and every $8 \mathrm{~h}$ thereafter and when clinically indicated. Respiratory depression was defined as a persistent respiratory rate $<10 \mathrm{bpm}$, oxygen partial pressure $(\mathrm{PaO} 2)<9.0 \mathrm{kPa}$ or a carbon dioxide partial pressure $(\mathrm{PaCo} 2)>$ $7.5 \mathrm{kPa}$.

The degree of sedation was monitored using a four-point scale ( $0=$ awake and alert, $1=$ drowsy, $2=$ mostly sleeping, $3=$ difficult or impossible to awaken).

Sedation scores were recorded at regular intervals after surgery.

The presence of nausea and vomiting was noted using a four-point scale $(0=$ no nausea or vomiting, $1=$ mild nausea, $2=$ sever nausea, $3=$ retching or vomiting).

Patients with a nausea score of 2 or 3 were given an i.v. bolus of metoclopramide $10 \mathrm{mg}$ and ondansteron $4 \mathrm{mg}$ if this was unsuccessful.

Other side effects possibly related to morphine or dexmedetomidine administration (bradycardia, bradypnea, urinary retention, and pruritus) were recorded for each patient. After $24 \mathrm{~h}$ patients were asked to score their level of satisfaction with their postoperative pain up to that time on a four-point scale $(0=$ totally dissatisfied, 1=moderately dissatisfied, 2=reasonably satisfied, 3=totally satisfied with pain relief).

Statistical analysis was performed using Mann-Whitney U-tests for pain scores, t-tests for parametric data, or chi-square test for categorical data.

Statistical calculations were carried out using computer programs Microsoft Excel version 7(Microsoft corporation, New York, USA) and statistical package for the social science (SPSS INC. Chicago, IL, USA). $\mathrm{P}<0.05$ was considered significant.

\section{Results}

Two patients were withdrawn from the study because of endotracheal intubation difficulty. Another patient was excluded from the analysis as he was unable to use the PCA because of sever vomiting and requested alternative analgesia $7 \mathrm{~h}$ after operation. One more patient was excluded due to sever postoperative bleeding. The remaining 24 patients were studied.

Patient characteristics were similar in the two groups (table1).

Many more males than females were recruited as OSA is more common in males.

Postoperative hemodynamic monitoring revealed no significant differences between the two groups. No patient required intervention as a result of cardiovascular problems.

The duration of anesthesia and surgery were similar in the two groups. Extubation time was significantly prolonged in dexmedetomidine group (16 $\pm 7 \mathrm{~min}$ vs. $11 \pm$ $6 \mathrm{~min})$ in the placebo group $(\mathrm{p}=0.074)$ (table2).

Figure 1 demonstrates the VAS in the two groups during the first $48 \mathrm{~h}$ after surgery. VAS scores were significantly greater during the first $2 \mathrm{~h}$ after tracheal extubation in the placebo group (fig1a) and were similar in the two groups thereafter(fig 1b). The mean VAS scores were never $>5 \mathrm{~cm}$ in the dexmedetomidine group during the first $2 \mathrm{~h}$ after surgery.

The time between extubation and the first 
W.Abd El Megid etal, .....

analgesic request in the PACU was significantly longer in the dexmedetomidine group (21 \pm 11 min vs. $9 \pm 4 \mathrm{~min}, \mathrm{p}=0.002$ ) (table2). The cumulative dose of morphine given by nurses in the PACU for titration was significantly greater in the placebo group $(21.7 \pm 11.1 \mathrm{mg})$ than in the dexmedetomidine group $(9.4 \pm 5.2 \mathrm{mg})(\mathrm{p}$ $=0.002) \quad$ (table2). PCA morphine consumption was significantly greater at $12 \mathrm{~h}$ and $24 \mathrm{~h}$ after surgery in the placebo group than in the dexmedetomidine group $(12 \mathrm{~h}$, $34 \pm 16.7$ and $18.1 \pm 10 \mathrm{mg}, 24 \mathrm{~h}, 65 \pm 29$ and $34.3 \pm 16.4 \mathrm{mg}$ respectively, $\mathrm{p}<0.05$ ) (Figure2). The cumulative morphine dose used during titration and PCA throughout the study was significantly greater in the placebo group than in the dexmedetomidine group $(135.7 \pm 37.4$ vs. $86.4 \pm 26.1 \mathrm{mg})$ respectively $(\mathrm{p}=0.001)$. In addition, six patients in the placebo group needed rescue analgesia in contrast to only one patient in the dexmedetomidine group ( $\mathrm{p}<0.05)$.

The sedation score did not differ significantly between the two groups during the $48 \mathrm{~h}$ after surgery (table3). There was no difference in the mean respiratory rate and $\mathrm{SpO} 2$ at any time between the two groups. One patient in the placebo group experienced a respiratory rate $<10 \mathrm{bpm}$ without desaturation below $95 \%$ and recovered rapidly without any specific treatment. As patients in the two groups received postoperative oxygen, $\mathrm{PaO} 2$ was constantly $>10 \mathrm{kPa}$ at $0,2,4$ and $6 \mathrm{~h}$ after surgery.

Postoperative nausea and vomiting were the most prevalent adverse events. The incidence of nausea and vomiting requiring treatment was significantly reduced in the dexmedetomidine group during the first $24 \mathrm{~h}$ after surgery (table3), although the severity scores were unchanged. A significantly more patients in the placebo group experienced itching than patients in the dexmedetomidine group (9 vs.3) respectively; $\mathrm{p}<0.05)$. Patient's satisfaction scores were significantly higher in group D (median 4 (range 2-4), compared with 3 (range 1-4) in group $\mathrm{p}),(\mathrm{p}<0.05)$. 
The Egyptian Journal of Hospital Medicine (2009) Vol., 36 : 421 - 433

Table1. Patients characteristics

\begin{tabular}{|c|c|c|c|}
\hline & $\begin{array}{r}\text { Group D } \\
(n=12)\end{array}$ & $\begin{array}{c}\text { Group P } \\
(n=12)\end{array}$ & $P$ value \\
\hline Age $(\mathrm{Yr})$ & $46.3(9.7)$ & $45.1(9.5)$ & 0.762 \\
\hline Gender (male/female) & $11 / 1$ & $10 / 2$ & 1.0 \\
\hline ASA (I/II) & $5 / 7$ & $4 / 8$ & 1.0 \\
\hline Height $(\mathrm{Cm})$ & $173.6(6.9)$ & $166.9(5.8)$ & 0.169 \\
\hline Weight (Kg) & $98.4(8.7)$ & $96(9.0)$ & 0.514 \\
\hline BMI (Kg. m²) & $32.7(3.3)$ & $32(2.9)$ & 0.587 \\
\hline $\begin{array}{l}\text { Arterial hypertension } \\
\text { (\%) }\end{array}$ & 46.8 & 61.1 & 0.188 \\
\hline Diabetes mellitus (\%) & 28.1 & 24.6 & 0.808 \\
\hline
\end{tabular}

$\mathrm{BMI}=$ body mass index.

Data are presented as mean (SD), absolute number or percentage of patients.

Table2. Duration of anesthesia and surgery, extubation time and postoperative morphine titration

\begin{tabular}{lccc}
\hline & $\begin{array}{c}\text { Group D } \\
(\mathbf{n = 1 2})\end{array}$ & $\begin{array}{c}\text { Group P } \\
(\mathbf{n}=12)\end{array}$ & P value \\
\hline $\begin{array}{l}\text { Duration of anesthesia } \\
\text { (min) }\end{array}$ & $96(54)$ & $101(42)$ & 0.802 \\
$\begin{array}{l}\text { Duration of surgery } \\
\text { (min) }\end{array}$ & $74(43)$ & $78(49)$ & 0.0834 \\
$\begin{array}{l}\text { Extubation time (min) } \\
\text { Time to first morphine }\end{array}$ & $16(7)$ & $11(6)^{*}$ & \\
titration (min) & $21(11)$ & $9(4)^{*}$ & 0.074 \\
$\begin{array}{l}\text { Morphine given by i.v. } \\
\text { titration in PACU (mg) }\end{array}$ & $9.4(5.2)$ & $21.7(11.1)^{*}$ & 0.002 \\
\hline
\end{tabular}

Data are presented as mean (SD). $* \mathrm{p}<0.05$

Table 3. Sedation scores and incidence of nausea and vomiting 
W.Abd El Megid etal, .....

\begin{tabular}{ccccc}
\hline Time after & \multicolumn{2}{c}{ Sedation Scores } & \multicolumn{2}{c}{ Nausea and Vomiting } \\
surgery $(\mathrm{h})$ & $\begin{array}{c}\text { Group D } \\
(\mathrm{n}=12)\end{array}$ & $\begin{array}{c}\text { Group P } \\
(\mathbf{n}=12)\end{array}$ & $\begin{array}{c}\text { Group D } \\
(\mathrm{n}=12)\end{array}$ & $\begin{array}{c}\text { Group P } \\
(\mathrm{n}=12)\end{array}$ \\
\hline $\mathbf{1 2}$ & $2(1-3)$ & $2(0-2)$ & 3 & $8^{*}$ \\
$\mathbf{2 4}$ & $1(0-2)$ & $1(0-2)$ & 2 & 4 \\
$\mathbf{3 6}$ & $1(0-2)$ & $1(0-2)$ & 1 & 4 \\
\hline
\end{tabular}

Data are presented as mean (SD or range) or absolute number. ${ }^{*} \mathrm{p}<0.05$

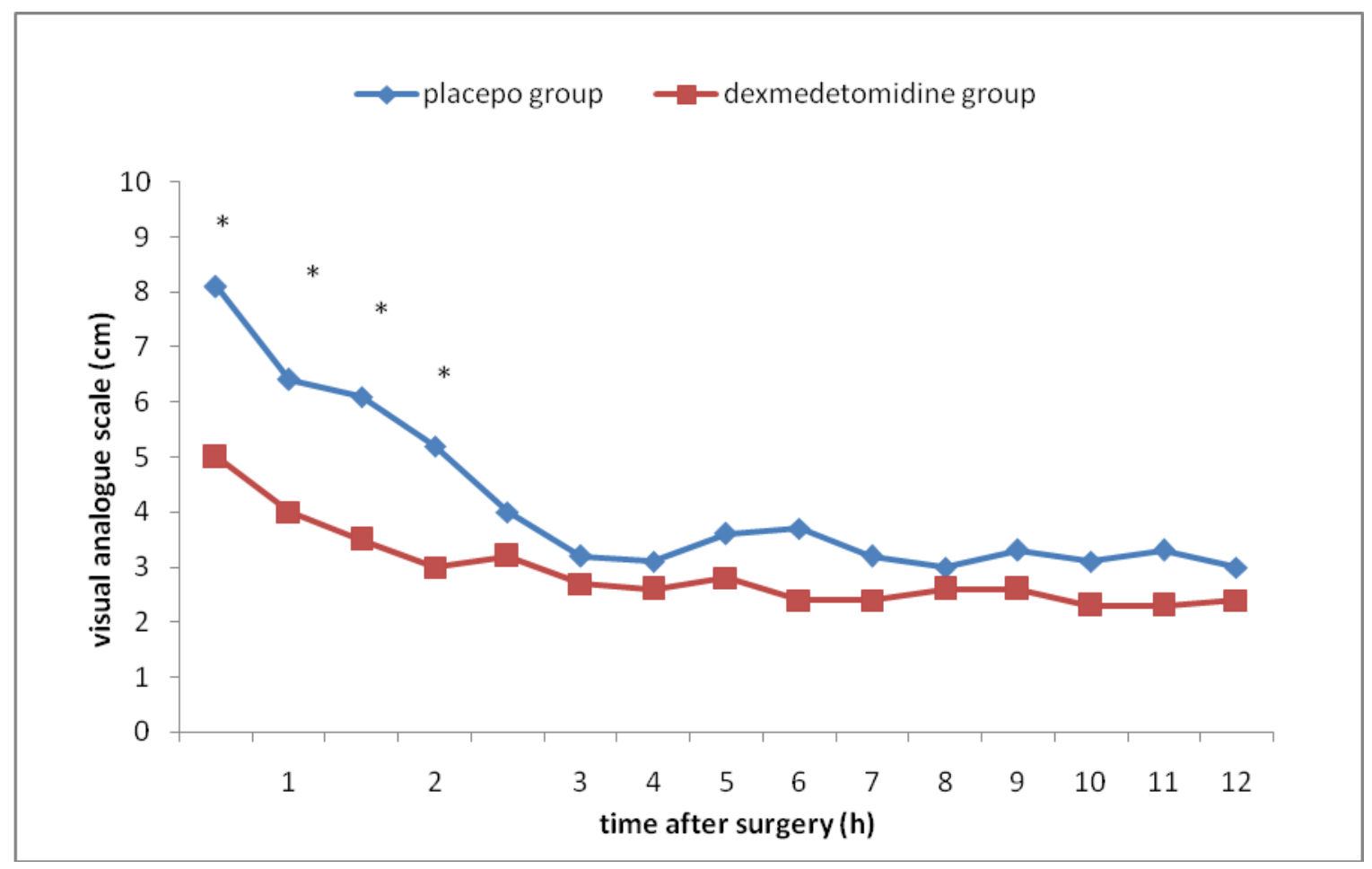

Fig 1a VAS pain scores $(0-10 \mathrm{~cm})$ in the two groups during the first $12 \mathrm{~h}$ after surgery. Values are mean and SD. Asterisks indicate statistically significant difference between the two groups $(\mathrm{p}<0.05)$. 


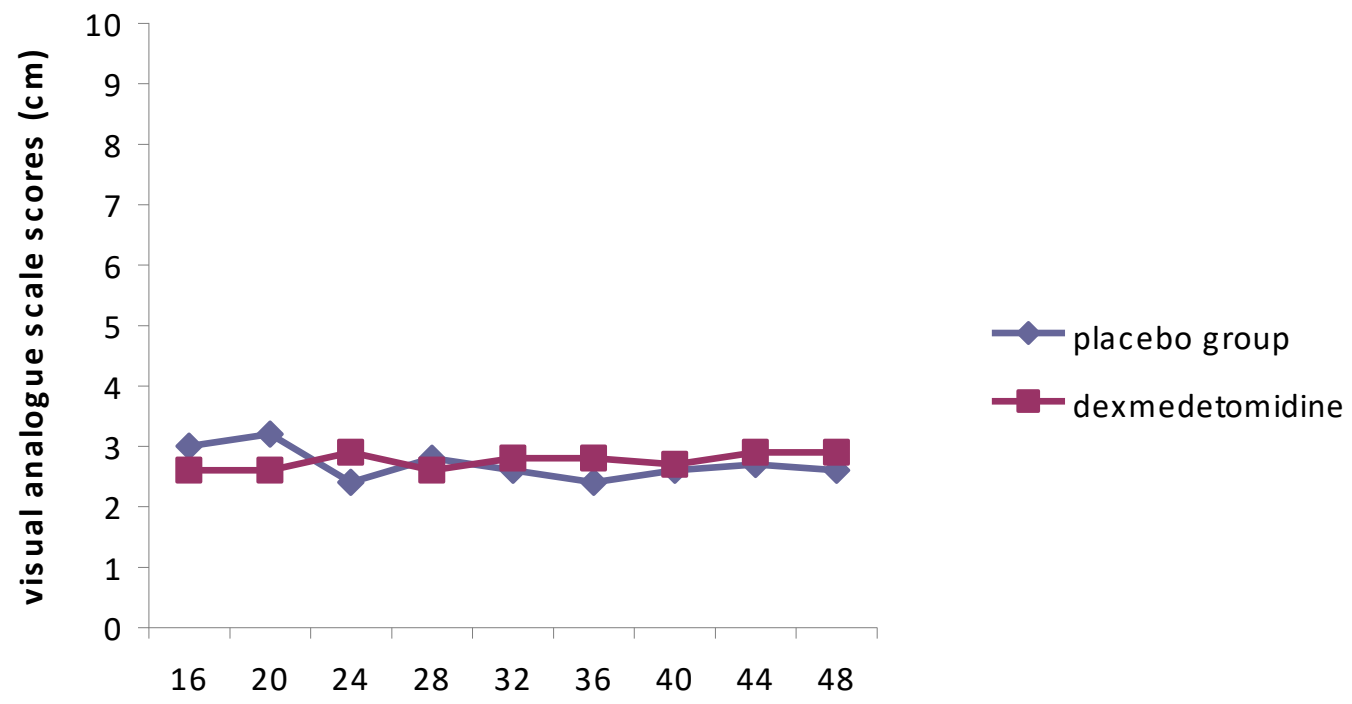

Fig 1b VAS pain scores $(0-10 \mathrm{~cm})$ in the two groups $16-48 \mathrm{~h}$ after surgery. Data are mean and SD.

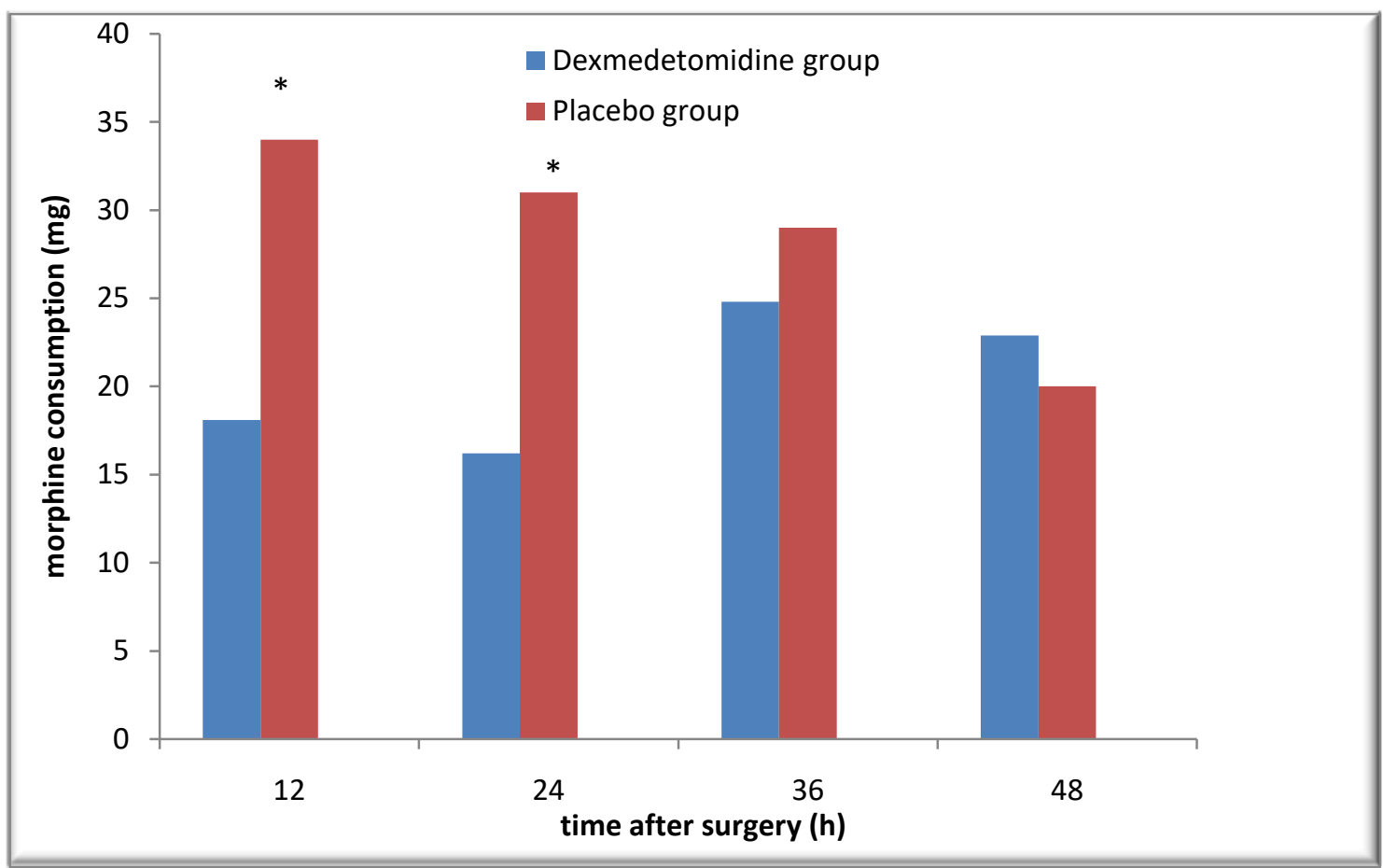

Fig 2 Cumulative postoperative PCA morphine consumption in the two groups during the $48 \mathrm{~h}$ after surgery. Data are presented as mean and SD. Asterisks indicate statistically significant differences between the two groups $(\mathrm{P}<0.05)$ 


\section{Discussion}

This study demonstrates that patients receiving continuous dexmedetomidine infusion for pain relief after UPPP required $52.7 \%$ less morphine by PCA in the first $24 \mathrm{~h}$ post operatively, compared with placebo group receiving only morphine.

Dexmedetomidine stimulates $\alpha 2$-adrenergic receptors and couples in an inhibitory fashion to the L-type calcium channels. These effects differ depending on receptor location; in the locus ceruleus, this stimulation provides sedation, while in the spinal cord it enhances analgesia (Kamibayashi and Maze 2000). The relatively high ratio of $\alpha 2: \alpha 1$ activity (1620:1 as compared with 220:1 for clonidine) accounts for the potent sedative effect of dexmedetomidine without unwanted cardiovascular effect from a1receptor activation (Hall et al., 2000). However, its use in large doses is complicated by transient hypertension and bradycardia via activation of $\alpha 2 \mathrm{~B}$ adrenoceptor located on smooth muscle cells in the resistance vessels and inhibition of cardiac sympathetic drive (Bloor et al., 1992). Because no particular dose of dexmedetomidine is strongly supported in the literature, in this study we used a dose of dexmedetomidine that was predicated to have no or minimal cardiovascular effects but still might be sufficient to produce sedation and analgesia. The loading dose was administrated approximately $30 \mathrm{~min}$ before the end of the procedure (over $20 \mathrm{~min}$ to minimize the effects on heart rate and blood pressure) in an attempt to attain a therapeutic level before the completion of surgery. (Arain et al., 2004) administrated dexmedetomidine at an initial loading dose of $1 \mu \mathrm{g} \mathrm{kg}^{-1}$ (over 10 min) followed by an infusion at $0.4 \mu \mathrm{g} \mathrm{kg}^{-1} \mathrm{~h}^{-1}$ initiated $30 \mathrm{~min}$ before the end of elective inpatient surgery.

They observed slower mean heart rates in the dexmedetomidine treated group during the early postoperative period with transient significant increase in MAP that lasted several minutes immediately after the initial loading dose of dexmedetomidine. The transient increase in MAP could be attributed to the direct effects of $\alpha 2$ receptor stimulation of vascular smooth muscle followed by an inhibition of sympathetic outflow that overrode the direct effects of dexmedetomidine on the vasculature. This might be an unavoidable effect of infusion $\alpha 2$ agonists, because the time differential between directly binding to vascular receptors and diffusion into the central nervous system to decrease sympathetic outflow during i.v. infusions might be ever present (Hall et al., 2000). However, in our study we did not observe this transient hypertension in the dexmedetomidine treated patients probably due to the relatively long period of infusion of the loading dose.

Obstructive sleep apnea is an increasingly common sleep disorder, which is of particular concern to anesthesiologists because it is associated with increased perioperative morbidity and mortality including respiratory obstruction after extubation or respiratory depression after opioid administration. Pain is one of the most important complications of UPPP (the most common surgical procedure performed by most otolaryngologists for treatment of OSA) despite the use of many medications (Zodpe et al., 2006). Analgesics must be administrated judiciously after UPPP as there is much evidence to suggest that anesthetic and narcotic agents increase the tendency for upper airway collapse; these agents also impair normal arousal mechanisms and may therefore worsen the severity of OSA (Mc Nicholas and Ryan 2006). Several studies have demonstrated the analgesic effects of dexmedetomidine. (Gurbet 
et al., 2006) investigated the efficacy of dexmedetomidine vs. morphine for postoperative analgesia after total abdominal hysterectomy. Prior to induction of anesthesia, one group received an initial loading dose of dexmedetomidine $1 \mu \mathrm{g} \mathrm{kg}^{-1}$ over $30 \mathrm{~min}$; followed by an infusion of 0.5 $\mu \mathrm{g} \mathrm{kg}^{-1} \mathrm{~h}^{-1}$ that was discontinued when surgery ended. The other group received the same volume of normal saline as a placebo. All patients used a PCA device to receive bolus doses of morphine after surgery. The groups had similar pain scores but the patients who received dexmedetomidine required a lower cumulative amount of morphine during the first $48 \mathrm{~h}$ after surgery.

(Arain et al., 2004) examined 34 patients scheduled for elective inpatient surgery and randomized them equally to receive either dexmedetomidine (initial loading dose of $1 \mu \mathrm{g}$ $\mathrm{kg}^{-1}$ over 10 min followed by $0.4 \mathrm{mg} \mathrm{kg}^{-1} \mathrm{~h}^{-1}$, discontinued at the end of surgery or morphine sulfate $\left(0.08 \mathrm{mg} \mathrm{kg}^{-1}\right) 30$ min before the end of surgery. The groups had similar pain scores but the morphine group required $66 \%$ more morphine to achieve this analgesic effect. (Hofer et al., 2005) reported a 433-kg morbidly obese patient with OSA and pulmonary hypertension who underwent Roux-en-Y gastric bypass. They substituted the intraoperative use of narcotics with a continuous infusion of dexmedetomidine $\left(0.7 \mu \mathrm{g} \mathrm{kg}^{-1} \quad \mathrm{~h}^{-1}\right)$ that was continued uninterrupted throughout the end of the first postoperative day. They found that the patient had lower narcotic requirement during the first postoperative day (48mg of morphine by PCA) while still receiving dexmedetomidine, compared to the second postoperative day (148 mg of morphine by PCA) with similar pain scores. In a recent study, involving 100 women undergoing total abdominal hysterectomy (Lin et al., 2009) added dexmedetomidine to PCA morphine for one of their patients' group. The authors observed that the patients in the dexmedetomidine group required 29\% less morphine and reported significantly lower pain scores from the second postoperative hour onwards and throughout the study. In agreement with these researches, the patients in our study who received dexmedetomidine required a lower cumulative amount of morphine during the first $24 \mathrm{~h}$ after surgery, which strongly supports the presence of dexmedetomidineinduced narcotic-sparing effect.

The analgesic effect of dexmedetomidine was also evident in our research by the significantly lower VAS scores observed during the first $2 \mathrm{~h}$ after surgery in the dexmedetomidine treated patients compared to the placebo group.

Previous animal studies have concluded that systemic administration of $\alpha 2$-adrenergic receptor agonists resulted in dose dependent antinociception and sedation responses (Buerkle and Yaksh 1998) whereas, human data revealed a clear dose-response relationship for sedation, but not for analgesia (Eisenach et al.,1996). A possible explanation of the variances between animal and human studies is that many of the animal experiments involved drug doses several orders of magnitude larger than those used in human trials (Hall et al., 2001). In human, a continuous dexmedetomidine infusion was found to maintain a unique level of sedation (patients appear to be asleep, but are readily arousable) without affecting respiration (Venn et al., 2000).

Dexmedetomidine is currently approved by the U.S. Food and Drug Administration for sedation of adults in the intensive care setting for up to $24 \mathrm{~h}$ during mechanical ventilation (Busick et al., 2008). Patients receiving dexmedetomidine can typically respond to commands and perform psychomotor tests when lightly roused from their sedate state 
without a need to decrease or stop the dexmedetomidine infusion (Hall et al., 2000). In our study, we found that the dexmedetomidine treated patients were sedated, they appeared to be asleep but they were easily aroused with verbal or physical stimuli. This is in agreement with the previous report by (Gurbet et al., 2006) who did not observe clinically important sedation in any of their patients who received dexmedetomidine infused at rate of $0.5 \mu \mathrm{g}$ $\mathrm{kg}^{-1} \mathrm{hr}^{-1}$.

The respiratory effects of dexmedetomidine have been greatly debated (Hall et al., 2000). In this study, we did not observe any clinically significant respiratory effect in any patient who received dexmedetomidine infusion at rate of $0.6 \mu \mathrm{g} \mathrm{kg}^{-1} \mathrm{~h}^{-1}$. Besides, as patients in the two groups received postoperative oxygen, $\mathrm{PaO} 2$ was constantly kept above $10 \mathrm{kPa}$ all through the postoperative period without significant changes in the PaCo2. (Venn

et al. 2000) demonstrated that, when used in spontaneously breathing patients in the intensive care unit after cardiac surgery and general surgery, dexmedetomidine reduced morphine requirements by over $50 \%$ while at the same time had no effect on respiratory rate, $\mathrm{SpO} 2$, arterial $\mathrm{PH}$, and $\mathrm{PaCO} 2$. Moreover, the $\mathrm{PaO} 2$ : $\mathrm{FiO} 2$ ratios were statistically higher in the dexmedetomidine group compared with their patients receiving morphine and midazolam boluses. On the other hand, (Belleville et al., 1992) reported that dexmedetomidine could be associated with episodes of obstructive apnea, and this was increasingly common at doses of 1 and $2 \mu \mathrm{g} \mathrm{kg}^{-1}$ that were given for two minutes and presumably associated with a rapid increase in sedation. There was a mild decrease in minute ventilation and an increase in $\mathrm{PaCo}$. Although all these effects are much less pronounced than those of opioids and other intravenous and volatile anesthetic agents, and appear to be similar in order of magnitude to those seen during profound sleep, we cannot exclude the possibility that more rapid loading doses might cause irregular breathing or obstructive apnea.

Thus an obstruction resulting in apnea is more likely related to the deep sedation and the oral and pharyngeal anatomical events that are common to deep sleep (Hall et al., 2000).

In conclusion, we found that continuous infusion of dexmedetomidine for pain relief after uvulopalatopharyngoplasty significantly reduces the amount of PCA morphine used by the patients postoperatively without affecting their ventilatory parameters and was associated with fewer morphine-related side effects. This novel drug could become a useful anesthetic adjuvant for patients with obstructive sleep apnea who are susceptible to narcotic-induced respiratory depression.

\section{References}

1- Arain SR, Ruehlow RM, Uhrich TD, Ebert TJ. (2004): The efficacy of dexmedetomidine versus morphine for postoperative analgesia after major inpatient surgery. Anesth Analg; 98: 153-58.

2- Belleville JP, Ward DS, Bloor BC, Maze M. (1992):Effects of intravenous dexmedetomidine in humans. 1. Sedation, ventilation, and metabolic rate. Anesthesiology ; 77: 1125-33.

3- Bloor BC, Ward DS, Belleville JP, Maze M. (1992):Effects of intravenous dexmedetomidine in humans.11. Hemodynamic changes. Anesthesiology; 77: 1134-42.

4- Buerkle H, Yaksh TL, Pharmacological evidence (1998) :for different alpha2-adrenergic receptor sites mediating analgesia and sedation in the rat. $\mathrm{Br}$ J Anaesth 1998;81:208-15.

5- Busick T, Kussman M, Scheidt T, Tobias JD. (2008): Preliminary experience with dexmedetomidine for monitored anesthesia care during ENT surgical procedures. Am J Ther; 15(6): 520-7.

6- Eisenach JC, De Kock M, Klimscha W. (1996): Alpha2 adrenergic agonists for regional anesthesia . A clinical review of clonidine (1984-1995). Anesthesiology; 85:655-74.

7- Gurbet A, Mogol EB, Turker G, Ugun F. Kaya

FN, Ozcan B. (2006) : Intraoperative infusion of Dexmedetomidine reduces perioperative analgesic 
requirements. Can J Anaesth; 53(7): 646-52.

8- Hall JE, Uhrich TD, Barney JA, Arain SR, Ebert TJ. (2000): Sedative, Amnestic, and analgesic properties of small-dose dexmedetomidine infusion. Anesth Analg; 90:699-705.

9- Hall JE, Uhrich TD, Ebert TJ. (2001) :Sedative, analgesic and cognitive effects of clonidine infusions in human. Br J Anaesth; 86:5-11.

10- Hofer RE, Sprung J, Sarr MG, Wedel DJ. (2005) :Anesthesia for a patient with morbid obesity using dexmedetomidine without narcotics. Can J Anaesth; 52: 176-80.

11- Kamibayashi T, Maze M. (2000) : Clinical uses of alpha2-adrenergic agonists.Anesthesiology; 93: 1345-49.

12- Kim J A, Lee J J. (2006) : Preoperative predictors of difficult intubation in patients with obstructive sleep apnea syndrome. Can J Anesth; 53(4): 393-7.

13- Lin TF, Yeh YC, Lin FS, Wang YP,Lin CJ, Sun WZ, Fan SZ. (2009): Effect of combining dexmedetomidine and morphine for intravenous patient-controlled analgesia. $\mathrm{Br} \mathrm{J}$ Anaesth; 102(1):117-22

14- Lundkvist k, Januszkiewicz A, Friberg D. (2009):Uvulopalatopharyngoplasty in 158 OSAS patients falling non-surgical treatment. Acta Otolaryngol 29:1-7.

15- Mc Nicholas WT, (2006) : Ryan S.Obstructive sleep apnea syndrome: translating science to clinical practice. Respirology; 11:136-44.
16- Nikanne E, Virtmaniemi J, Aho M, Kokki H. (2003): ketoprofen for post operative pain after uvulopalatopharyngoplasty and tonsillectomy: two week follow up study. Otolaryngol Head Neck Surg; 129(5):577-81.

17- Patrocinio LG, Rangel M, Miziara GSM, Rodrigues AM, Partrocinio J, Partrocinio TG. (2007) :A comparative study between ketorolac and ketoprofen in postoperative pain after uvulopalatopharyngoplasty. Rev Bras Otorhinolaryngol 73(3): 339-42.

18- Riker R R, Shehabi Y, Bokesch PM, Ceraso D, Wisemandle W, koura F, Whitten P, Margolis BD, Byrne DW, Ely EW, Rocha MG. (2009) : Safety and efficacy of Dexmedetomidine compared with Midazolam. JAMA 301(5): 489-99.

19- Venn RM, Hell J, Grounds RM. (2000) Respiratory effects of dexmedetomidine in the surgical patient requiring intensive care. Crit Care; 4:302-8.

20- Virtaniemi J, kokki H, Nikanne E, Aho $M$. (2009) :Ketoprofen and Fentanyl for pain after uvulopalatopharyngoplasty and tonsillectomy. Laryngoscope 109(12):1950-54.

21- Zodpe P, Cho J G, Kang H J, Hwang S J, Lee H. (2006) : Efficacy of sucralfate in the postoperative management of uvulopalatopharyngoplasty. Arch otolaryngol Head Neck Surg; 132: 1082-5. 


\section{أستخدام عقار الايكساميديتيمودين لتسكين الآلام بعد

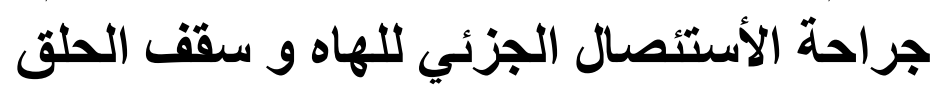 والبلعوم واللوزتين

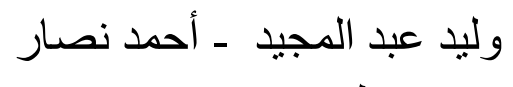 \\ طب عين شمس}

إن عقار الديكساميديتيمودين هومحفز ألفا2 وله تأثير مسكن للآلام.

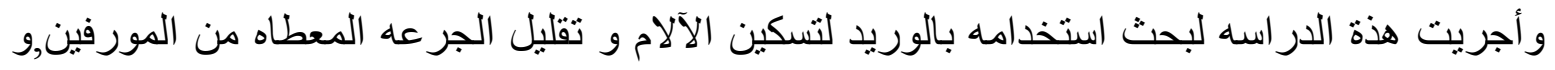

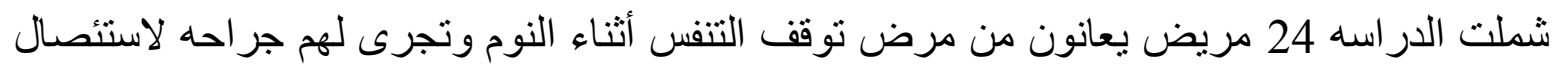

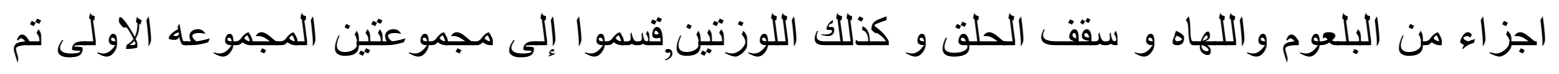

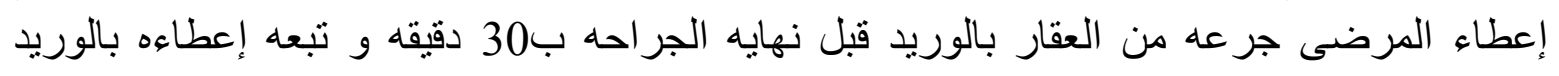
بالتنقيط لمدة 24 ساعهاء و المجمو عه الثانيه كانت مجمو عه التحكم, و تم إعطاء مورفين للمجمو عتين بعد الجر احه لتسكين الآلام

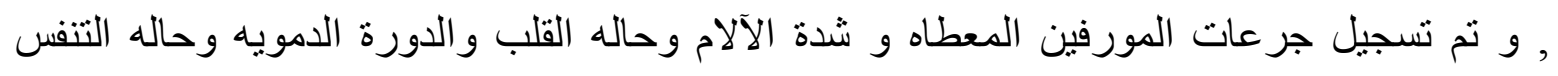

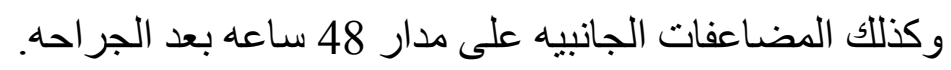

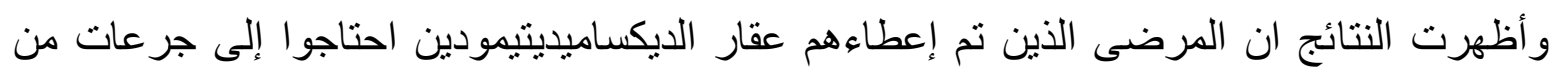

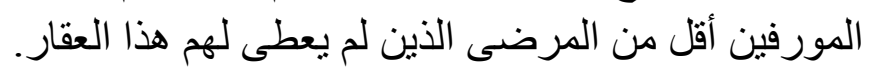

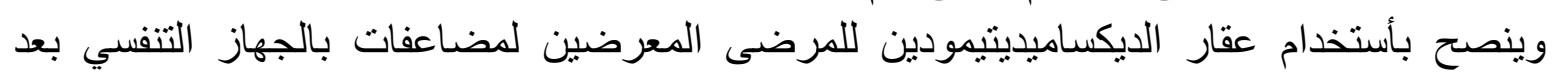

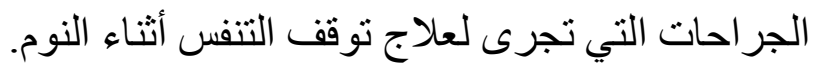

